\title{
El agua en La Curée de Émile Zola como reflejo del alma de su protagonista Renée Saccard
}

\section{Sánchez Luque, María Custodia}

Universidad Complutense de Madrid, luque20001@hotmail.com

\begin{abstract}
Resumen
Existen tres espacios acuáticos en la novela La Curée, que simbolizan los diferentes aspectos de la complicada personalidad de su protagonista, Renée Saccard. El análisis de estos tres lugares -los lagos del bosque de Boulogne, el estanque del invernadero del palacete Saccard, y las vistas del Sena- nos permite ver que se erigen en actantes del conflicto. La promenade del bosque de Boulogne, que con su decoración artificial y su lago de una limpieza demasiado cristalina, se asimila al mundo frívolo de los nuevos ricos parisinos, es el reflejo de la existencia absurda y vacía de Renée. En el ambiente sensual del invernadero y gracias a la influencia tentadora del agua, Renée se olvida de los convencionalismos burgueses y muestra su lado voluptuoso, transformándose en mujer fatal. Finalmente, las dos descripciones que se hacen del Sena, remiten a las grandes carencias emocionales de Renée, motivadas por la ausencia de figura materna. En efecto, el río, al transmitir las nociones de admiración y seguridad, se identifica con la imagen de la madre.
\end{abstract}

Palabras clave: Zola; agua; jardín; invernadero; Segundo Imperio.

\section{Résumé}

Il y a trois espaces aquatiques dans le roman La Curée symbolisant les différents aspects de la complexe personnalité de sa protagoniste, Renée Saccard. L'analyse de ces trois lieux-les lacs du Bois de Boulogne, le bassin de la serre de l'hôtel Saccard, et les vues de la Seine- nous permet de voir qu'ils agissent en actants de l'intrigue. La promenade du Bois de Boulogne, dont la décoration artificielle et le lac d'une propreté trop cristalline, s'assimilent au monde frivole des nouveaux riches Parisiens, est un reflet de l'existence absurde et vide de Renée. Dans l'ambiance sensuelle de la serre et sous l'influence irrésistible de l'eau, Renée oublie les conventions bourgeoises et montre son côté voluptueux, devenant une femme fatale. Finalement, les deux descriptions de la Seine, renvoient au manque d'affection dont Renée souffre, découlant de l'absence de la figure maternelle. En effet, la rivière, en transmettant les notions d'admiration et de la sécurité, s'identifie avec l'image de la mère.

Mots-clés: Zola; eau; jardin; serre; Second Empire.

\begin{abstract}
There are three aquatic environments in the novel La Curée, symbolizing the different aspects of the complex personality of its main character, Renee Saccard. The analysis of these three places - the lakes of the Bois de Boulogne, the pond in the greenhouse of Saccard's mansion, and the views of the river Seineallows us to see that they set themselves up as actants of the intrigue. The promenade of the Bois de Boulogne, which reminds us of the frivolous world of the Parisians nouveau riche, with its artificial decor and crystal-clear water lakes, is a reflection of Renée's absurd and empty existence. In the sensual atmosphere of the greenhouse and thanks to the tempting influence of water, Renée forgets the bourgeois conventions and shows her voluptuous side, becoming a femme fatale. Finally, the two descriptions of the river Seine refer to Renée's emotional deprivations, motivated by the absence of the maternal figure. Indeed, the river, by communicating the notions of admiration and security, is identified with the image of the mother.
\end{abstract}

Keywords: Zola; water; garden; greenhouse; Second French Empire. 


\section{Introducción}

El propósito de esta comunicación es analizar tres espacios acuáticos de la novela La Curée de Émile Zola, como emblema de la complejidad psicológica de su protagonista, Renée Saccard. Estos espacios son los lagos del bosque de Boulogne; el estanque y el ambiente húmedo del invernadero del palacete en el que Renée reside con su marido, Aristide Saccard, y, en tercer lugar, las vistas del Sena desde la habitación infantil de la casa natal de Renée, en la isla de San Luis. De cada uno de los tres espacios hay dos grandes descripciones en la novela que aparecen en los momentos clave del desarrollo de la intriga y que son reflejo de las diferentes facetas de la vida de Renée.

Antes de continuar con nuestro análisis, debemos hacer unas precisiones sobre el tratamiento del agua en Émile Zola. Como apunta Marcel Girard, los biógrafos del novelista han presentado sus salidas al campo de los alrededores de Aixen-Provence en la época de su adolescencia, en compañía de Cézanne, como hechos que han condicionado enormemente su obra. Las experiencias vividas durante sus excursiones a la orilla y a las islas del río Arc, fueron el nacimiento de sensaciones indelebles que afectaron a su personalidad y a su universo novelesco de manera fundamental. Cabe pensar que pueda ser ésta una de las causas que explican el hecho de que el agua ocupe más tarde un lugar destacado en sus novelas.

\section{Agua en el estanque del Bois de Boulogne}

Es muy significativo que la novela comience con el paseo que da Renée alrededor del lago del Bois de Boulogne, el escenario por excelencia de la fiesta imperial, el lugar donde confluye la alta sociedad parisina para hacer alarde de su riqueza $^{1}$. La parada que la calesa de Renée se ve obligada a hacer, por la congestión de carruajes, le sirve de excusa al autor para describir, a través de la mirada de la protagonista, ese cuadro que forman el lago y los árboles, la famosa promenade del Bois de Boulogne, el epicentro de la sociedad parisina durante la época dorada del Segundo Imperio ${ }^{2}$.

Este escenario acuático, más que por su encantador aspecto pintoresco, llegó a ser significativo en la época debido al uso que se hizo de él: el recorrido en torno a los lagos, que se convirtió en su función más importante. Cada tarde, una multitud de parisinos de la clase alta, acudía al bosque en carruajes y en caballos, y daba varias vueltas alrededor de este espacio ${ }^{3}$. En su artículo «From place to espace: Napoleon III’s transformation of the Bois de Boulogne», Richard S. Hopkins pone de relieve hasta qué punto esta práctica social hacía que este lugar pasara de ser simplemente un bonito escenario acuático, a centro vital de información así como una red de comunicación para aquellos que participaban en ese febril consumo ostentoso del París del Segundo Imperio. A este respecto, tenemos el testimonio del escritor y periodista de la época Alfred Delvau, quien en su guía de París escrita en 1867, explica:

Si le Bois de Boulogne n'est plus le bois favori des poètes, des amoureux et de suicides, en revanche il est la promenade privilégiée d’une bonne moitié de Paris, la plus riche, bien entendu. Chaque jour, de deux à quatre, l'avenue de l’Impératrice [...] est littéralement encombrée d’équipages et de cavaliers. [...] J’oserais vous prier, monsieur et cher

\footnotetext{
${ }^{1}$ El Bois de Boulogne, antiguo terreno de caza de los reyes de Francia, se puso de moda como lugar de esparcimiento y paseo a partir del siglo XVIII. En 1848 pasa a manos del Estado, que lo cede a la villa de París en el año 1852. Fue remodelado por Napoleón III siguiendo el estilo del jardín naturalista inglés, con sus formas naturales y sus senderos serpenteantes. El II Imperio, hará del jardín inglés su estilo oficial, al encontrar en él una mezcla de romanticismo aristocrático y de naturalismo burgués.

${ }^{2}$ En un principio sólo se ideó un único lago, diseñado por el jardinero paisajista Louis Varé. Este proyecto original resultó ser, sin embargo, un rotundo fracaso, ya que el agua de este lago se filtraba continuamente empantanando la tierra de alrededor. Haussmann animó al emperador a reemplazar a Varé por el reputado ingeniero Adolphe Alphand. La solución de éste consistió en diseñar dos lagos en vez de uno y sellarlos con una buena capa de hormigón para evitar filtraciones. El "Petit Lac" fue el más pequeño, con una superficie de 30.000 m2. Sin embargo, era conocido como el lago superior, por estar ubicado en una zona más alta que el otro. El "Grand Lac", mucho más grande que el anterior, tenía una superficie de unos $190.000 \mathrm{~m} 2$. Alphand construyó también dos islas en el centro del lago grande, las cuales constituirían un punto focal. Todo el conjunto fue poblado por una vegetación bastante densa, lo que creó un delicioso efecto pintoresco. Alphand rodeó los lagos con un sendero para carruajes, con el fin de proporcionar múltiples puntos de vista de todo el conjunto (Hopkins, 2003).

${ }^{3}$ Mientras que el Bois de Boulogne pasó a ser el escenario de la mundanidad, en oposición a éste, el Bois de Vincennes, en el otro extremo de la ciudad, se convirtió en el parque de esparcimiento y paseo de la gente del pueblo, de ahí que éste conservase áreas en las que la vegetación crecía libremente y donde el paseante podía apropiarse verdaderamente del espacio, como si se encontrara en una excursión campestre. Luisa Limido pone de relieve que en este último parque la voluntad de la naturaleza se encontraba menos contrariada que en el Bois de Boulogne. Esta es la razón por la que el Bois de Vincennes fue menos criticado por ciertos periodistas, políticos y eruditos de la época que denostaban el reinado de Napoleón III. Así, Ferdinand de Lasteyrie, uno de los principales censores de este régimen, mostró su preferencia por el Bois de Vincennes y se quejaba de que en el Bois de Boulogne se forzaba la naturaleza (Limido, 2002: 147).
} 
étranger, de ne pas prendre ces élégants et ces élégantes pour ce qu'ils ne sont pas, mais bien plutôt pour ce qu'ils sont pour la plupart, des faux dandies et des femmes de manège. [...] Voilà la Duthé, la beauté à la mode. Voilà mademoiselle Raucourt, une tragédienne; mademoiselle Beaupré, une impure [...] des ducs, des comtes, des barons et des chevaliers, de tous les ordres. Et les voitures donc!, wiskys, carrosses, milords, broughams... (Delvau, 1867: pp. 31-33).

Hay un hilo conductor entre la descripción de la primera escena en el Bois de Boulogne con la que comienza la novela y la segunda descripción del capítulo VII, con la que finaliza. Al principio de la obra, este espacio es sinónimo de la grandeza de Renée. Ella es la reina de la fiesta imperial, que brilla en los altos círculos de la sociedad parisina. En la segunda presentación de este lugar, al final de la novela, Renée es una mujer fracasada. El agua refleja el universo mundano en el que evoluciona la heroína. Después de haber sido el símbolo de la ascensión social de Renée, la promenade del Bois de Boulogne se convierte en el de su decadencia.

Esta promenade, con su decoración artificial y su lago de un agua demasiado cristalina, sin una sola espuma, se asimila al mundo frívolo de los nuevos ricos parisinos, es el reflejo de la existencia absurda y vacía de Renée, esa gran mundana que sólo de cara a la galería, posee todo cuanto desea: majestuosos carruajes, espléndidos caballos y vestidos de los que la prensa habla.

En su crónica del periódico Gaulois, de primavera de 1869, Zola expresa su añoranza por los antiguos horizontes, las viejas casas, el ancestral bosque de Boulogne, en alusión a las transformaciones ordenadas por Napoleón III, tanto en el casco urbano de París como en este emblemático bosque del oeste de la ciudad, al que compara, tras las obras de remodelación, con un decorado de teatro: «D’un bois [on] fait un bouquet [...] C'est l'affaire d'un entracte: la toile est tombée, les machinistes posent les rochers, regardent si le robinet de la rivière est en état, plantent quelques arbres en guise de coulisses» (Zola: 1869, citado por Duchet, 1993: 19-20).

En ese sentido, cabe destacar que el conocimiento profundo de la obra de Zola nos pone en contacto, por un lado, con el carácter conflictual que adquiere en su imaginario la relación arquitectura-naturaleza. Chiwaki Shinoda, al reflexionar sobre las razones que han podido influir en el interés por la exuberancia vegetal de ciertos literatos franceses del último tercio del siglo XIX, entre los que se encuentra Zola, apunta a circunstancias como el peligro de desaparición por el que pasaba el bosque francés en la época, como consecuencia de la vorágine urbanística; el propio Zola se lamenta en su artículo de La Cloche del 12 de abril de 1870, Ce que disent les bois: «Hélas! On coupe en ce moment ma chère fôret! [...] Toute la forêt, navrée, devenue lugubre, pleurait» (Zola, 1870, cita de Shinoda, 2001: 59). Los bosques se talaban para construir barcos de guerra con los troncos de los árboles, y para aprovechar las ramas para la calefacción; en todos los bosques se construían fundiciones y hornos de vidrio; se expulsaba a los rebaños, etc.

Por otro lado, sobresale su faceta ecologista. La glorificación de la naturaleza de la que participa Zola nos recuerda en cierta medida a la de algunas cosmovisiones antiguas, según las cuales la naturaleza era algo sagrado que debía venerarse y respetarse. A este respecto, es oportuno evocar el artículo «Ecoficciones e imaginarios del agua y su importancia para la memoria cultural y la sostenibilidad», en el que Martos Núñez y Martos García afirman lo siguiente:

\begin{abstract}
La naturaleza se ha leído en muchas tradiciones orales y/o literarias como una especie de “decorado” (v.gr. el locus amoenus de los clásicos) e, igual que en los mitos matriarcales de la Vieja Europa (Gimbutas, 1991), como una fuerza caótica e incluso demoníaca que había que doblegar. Es más, la cultura de la violencia que está en la base de los sacrificios rituales (infanticidios, por ejemplo) del mundo fenicio o maya se argumentaba a base de las dádivas $\mathrm{u}$ ofrendas debidas para provocar la fertilidad o la lluvia. [...] Sustituir una perspectiva antropocéntrica o androcéntrica por otra más abierta que coloque en el foco "el-hombre-en-el-medio-ambiente” y no de forma separada o beligerante (el hombre vs. la naturaleza) no es fácil (Martos Núñez, Martos García, 2013).
\end{abstract}

Las personas del siglo XXI estamos, por suerte, familiarizadas con los discursos que abogan por modelos de sociedades donde se busque una plena comunicación con la naturaleza. Sin embargo, lo que resulta sorprendente es la modernidad que a este respecto demostró el autor de La Curée, por su clarividencia al negar los argumentos que reducían el papel de la naturaleza a una simple fuente de provisión de materias primas al servicio de la civilización. 
Zola tiene tanto que decir y tanto que denunciar que coloca ya al lector, desde las primeras páginas de la obra, ante la realidad decadente del Segundo Imperio. Al empezar la novela presentando el cuadro de la alta sociedad parisina en el Bois de Boulogne, el autor quiere resaltar que todo este lujo no crea felicidad, como se pone de manifiesto a través del personaje de Renée, desestabilizado por este universo de lujos y dispendios a ultranza. En la segunda descripción de este espacio, en la última etapa de su vida, se puede constatar hasta qué punto este medio social ha destruido a Renée.

Hay que preguntarse entonces por qué procesos ha pasado esta mujer en el transcurso del tiempo que separa estos dos momentos. El análisis de los escenarios acuáticos nos va a ayudar en ello, ya que éstos reflejan los diferentes aspectos de la personalidad de Renée.

Es aquí donde entra también en juego su marido, Aristide Saccard, quien para realizar su plan de convertirse en un próspero especulador inmobiliario, tras enviudar de su primera mujer, se casa con Renée, una rica burguesa que no es para él más que un eficaz instrumento para amasar una gran fortuna, no sólo por el gran capital inmobiliario que la joven ha recibido como dote, sino también por su extraordinaria belleza.

El plan urdido por Saccard consiste en arrojar a Renée a una vida de derroches y placeres locos, para que ella termine angustiada por las deudas, y se vea obligada a desprenderse de sus terrenos en favor de su marido. Este plan tiene un desarrollo que va desde el comienzo hasta el final de la obra, y da lugar a que el progresivo enriquecimiento de Saccard evolucione de forma paralela a la paulatina pauperización económica y moral de su esposa. Esta vida de abuso de toda clase de goces a la que Renée es lanzada, termina por hastiarla y por impulsarla a buscar otros goces más fuertes, pues ya no encuentra satisfacción en nada.

Esta necesidad de experiencias que aplaquen el aburrimiento que la invade, algo «qui n'arrivât à personne, qu'on ne rencontrât pas tous les jours, qui fût une jouissance rare, inconnue», se va a canalizar en Renée a través de un frenesí sensual que la llevará al adulterio.

\section{Elemento acuático en el invernadero}

Este estado de cosas introduce el segundo escenario acuático de la novela, el del invernadero del palacete Saccard, pues es en este espacio donde Renée se despoja de ese disfraz de gran dama de la alta sociedad con el que la vemos en el escenario anterior y muestra su lado libidinoso, transformándose en mujer fatal. Dos ingredientes desempeñan aquí el papel tentador: la vegetación y el agua. Sólo bajo la influencia de estos dos elementos, Renée será capaz de ceder a la transgresión de convertirse en la amante de su hijastro.

Si nuestra heroína se transforma en mujer fatal en el invernadero, es porque es éste el único lugar donde puede ser ella misma. Renée desea tomar el control de su cuerpo, que hasta ese momento sólo había sido un elemento de placer visual masculino. Como ya hemos mencionado, Renée no es para Saccard más que un objeto, un medio para la consecución de sus fines, por eso es tan decisivo para ella el contar con un espacio donde tomar las riendas de su vida. Este espacio será el invernadero (Sánchez Luque, 2016).

Las dos descripciones de las escenas aquí desarrolladas también se organizan en torno a un punto de agua: el estanque central, al que la atmósfera malsana y caliente del invernadero transforma, siguiendo a Jean-François Tonard, en un mar de fuego que recuerda al caldero de bruja de L'Assommoir.

Por otro lado la humedad que impera en el lugar evoca la propia de los climas tropicales, que despiertan los sentidos. El invernadero es presentado como un espacio inquietante, propicio para el descubrimiento de capacidades amorosas insospechadas, conforme a la mentalidad del siglo XIX, tan cargada de principios puritanos, para la que el mundo tropical de los invernaderos significaba una libertad sexual que no entendía de prohibiciones ni de limitaciones.

Otro aspecto de la humedad del invernadero es el de útero materno. Como apunta Meyrat-Vol, la protagonista de $L a$ Curée, al penetrar en este espacio, al final del capítulo I, entra en un estado de ensoñación despierta y, mientras dura éste, la mujer realiza una reinserción inconsciente en la matriz protectora. Renée huye de la sociedad temible y hostil encarnada por sus invitados a la cena, para refugiarse en el sustituto cavernoso del vientre materno. En este sentido, abundan las imágenes que evocan la idea de regressus ad uterum: la isotopía de la noche, del hueco, del agua, de la leche, de la tibieza, 
de lo vegetal y de la feminidad. La liquidez a la que tanto se alude en la descripción, se parece al líquido amniótico protector que envuelve el feto.

Por otro lado, no es casual que las metáforas acuáticas aparezcan sólo en la primera de las dos grandes descripciones del invernadero, bien en forma de salto de agua:

«[...] de minces colonnettes de fer montaient d'un jet soutenir le vitrail cintré»

«De jets souples s'accrochant aux branches, franchissant le vide d'un vol hardi»

«Sur sa tête, elle sentait le jet des Palmiers».

De lluvia:

«les grands Bambous de l’Inde montaient droits [...] faisant tomber de haut leurs pluie légère de feuilles» «tandis que, de la dentelle des Fougères, tombaient en pluie fine des gouttes de clarté».

De leche:

«A cette heure, des globes de verre dépoli éclairaient les feuillages de nappes laiteuses».

De gotas de agua:

«Dans sa robe de satin vert, la gorge et la tête rougissantes, mouillées des gouttes claires de ses diamants... »

O de fluir:

«sur les éventails vernis des Lataniers, un flot de lueurs blanches coulait»

Los dos elementos del invernadero que desempeñan el papel tentador, el agua y la vegetación, se complementan: cada mención al elemento acuático en la primera descripción del capítulo I, puede ser interpretada como una metáfora sexual que encuentra su eco en el acto carnal referido en la segunda descripción del capítulo IV. Se comienza de una forma relativamente moderada en la primera descripción, cuando la pasión de la mujer no se ha materializado todavía, para alcanzar el paroxismo en la segunda descripción, coincidiendo con la etapa de apogeo en la relación entre Renée y su hijastro Maxime. Los deseos inconfesados a los que se hace referencia en el capítulo I, se han materializado ya al final del capítulo IV.

\section{El Sena}

Finalmente, las dos exposiciones del Sena, que forman parte de sendas panorámicas desde la habitación en la que Renée jugaba de niña con su hermana, en su casa natal de la isla de San Luis, evocan la faceta más vulnerable de la mujer, descubren la triste verdad del vacío que se esconde bajo las apariencias brillantes de la vida mundana, ya que remiten a sus grandes carencias emocionales, motivadas por la ausencia de la madre. En efecto, el río aparece como un ser mítico, que viene de un lugar lejano y desconocido, que pone a la niña en contacto con el mundo de la ensoñación, se acerca para saludar, y continúa su camino, desapareciendo nuevamente. El río se identifica con la imagen de la madre — que ha estado ausente en la vida de Renée—-, pues transmite admiración y seguridad, al adoptar la dulzura de un titán domado. Renée 
encuentra su redención en ese paisaje que tantas veces había contemplado durante su infancia. El agua es aquí fuente de vida, medio de purificación y regeneración.

En las dos presentaciones, Zola le da al Sena una plena existencia literaria. Es en el entorno de los paisajes acuáticos de Aix en Provence donde Zola ha tenido experiencias verdaderamente felices que han forjado su personalidad. También Renée pudo haberlas tenido junto a esa madre de la que nunca disfrutó. La visión del Sena es tan intensa que a Zola le cuesta percibirlo como un elemento sin vida.

En síntesis, creemos que Zola busca resaltar aquí la huella de la ausencia de la figura materna en Renée. Y no es insustancial el hecho de que la palabra Sena sea de género femenino en el idioma francés, ya que esto contribuye a facilitar esa percepción del río como madre.

Como manifiesta Bernard Joly en su artículo Le chaud et le froid dans La Curée, la vista del Sena representaba para las dos niñas, Renée y su hermana, una especie de hada con múltiples vestimentas:

\begin{abstract}
Et la grande joie de la chambre des enfants était encore le vaste horizon [...] l'âme de tout cela, [...] c'était la Seine, la rivière vivante; elle venait de loin, du bord vague et tremblant de l'horizon, elle sortait de là-bas, du rêve, pour couler droit aux enfants. [...] Les petites aimaient la géante, elles s’emplissaient les yeux de sa coulée colossale, de cet éternel flot grondant qui roulait vers elles, comme pour les atteindre, et qu'elles sentaient se fendre et disparaître à droite et à gauche, dans l'inconnu, avec une douceur de titan dompté. Par les beaux jours, par les matinées de ciel bleu, elles se trouvaient ravies des belles robes de la Seine; c’étaient des robes changeantes qui passaient du bleu au vert, avec mille teintes d'une délicatesse infinie. [...] Au loin, surtout, l'étoffe devenait admirable et précieuse, comme la gaze enchantée d'une tunique de fée (Zola, 1871).
\end{abstract}

Al final del capítulo VII, Renée hace una segunda visita a la habitación infantil de su casa natal. Es un regreso muy simbólico, pues ha transcurrido toda una vida desde su época de niña, evocada en la primera descripción del capítulo II. La heroína vuelve sobrepasada por su experiencia vital de un mundo hostil, como si acudiera a refugiarse en el regazo de la madre, buscando reencontrarse con las nociones de estabilidad, abrigo y amparo, que antaño el Sena le inspiraba. Metáforas como la de los brazos abiertos « s’ouvrant autour d'elles, derrière elles, en deux bras », o la del vestido, « sa belle robe de soie verte, mouchetée de flammes blanches », refuerzan esta idea de la madre protectora.

\title{
Conclusión
}

El análisis de los imaginarios del agua nos enseña que a menudo las aguas tienen más de una interpretación y que generan incluso símbolos divergentes. Así, hemos visto que la Renée mundana sólo podía exhibir su belleza en la promenade alrededor del estanque del Bois de Boulogne, el escenario paradigmático de la fiesta imperial, esa especie de teatro del mundo en el que reina la apariencia, en medio de una naturaleza ficticia como así es también esa vida que Renée lleva de cara a la galería. El crimen del incesto sólo podía consumarse en ese templo del exceso erótico que es el invernadero, impregnado de la humedad propia de los climas tropicales, que excita los sentidos, construido en el nuevo París imperial; y la mujer sólo podía arrepentirse de sus acciones contemplando la panorámica del Sena, desde la habitación de juegos de su casa natal en el viejo Paris, en los lugares de su infancia y de su inocencia perdida y malgastada.

\section{Referencias bibliográficas}

Delvau, Alfred (1867). Les Plaisirs de Paris: Guide pratique et illustré. Paris: A. Fauré.

GimbutAs, Marija (1991). The civilization of the goddess. Joan Marler.

GIRARD, Marcel (1972). «Les “baignades” d’Émile Zola». En XXIIIe Congrès de l’Association Internationale des Études Françaises. Paris. p. 95-111.

Hopkins, Richard S. (2003). «From place to espace: Napoleon III’s transformation of the Bois de Boulogne». $<$ http://quod.lib.umich.edu/w/wsfh/0642292.0031.012/--from-place-to-escape-napoleon-iiistransformation?rgn=main;view=fulltext $>$ [Consultado el 12 febrero 2016]. 
JoLY, Bernard (1977). «Le chaud et le froid dans La Curée». En Les Cahiers naturalistes, No 51, < http://www.archiveszoliennes.fr/ancien/index.php?partie=4\&souspartie=1\&vari=422> [Consultado el 1 de octubre de 2016].

Limido, Luisa (2002). L'Art des jardins sous le Second Empire: Jean-Pierre Barillet-Deschamps, 1824-1873. Seyssel: Champ Vallon.

Martos NuñEz, Eloy y MARTos García, Alberto. «Ecoficciones e imaginarios del agua y su importancia para la memoria cultural y la sostenibilidad». En Alpha, revista de artes, letras y filosofía, n ${ }^{\circ} 36$. <https://dialnet.unirioja.es/revista/5902/A/2013> [Consultado el 5 abril 2016].

Meyrat-Vol, Claire (1997). L'Imaginaire végétal dans les Rougon-Macquart d'Émile Zola le régime nocturne. Thèse de doctorat. Université de Lille III.

SANCHEZ LUQUE, María Custodia (2016). Los jardines « pintados » de Émile Zola, lugares de encuentro entre literatura y arte. Tesis de doctorado. Universidad Complutense de Madrid.

SHINODA, Chiwaki (2001). «Exuberance végétale chez Mirbeau et Zola». En Cahiers Octave Mirbeau, no 8, p. 58-73.

TONARD, Jean-François (1994). Thématique et symbolique de l'espace clos dans le cycle des Rougon-Macquart d'Emile Zola. Paris: Peter Lang.

ZolA, Émile (1971). La Curée. Paris: GF Flammarion. Préface par Claude Duchet. 